Western University Scholarship@Western

Electrical and Computer Engineering Publications Electrical and Computer Engineering Department

$12-2015$

\title{
Students' Perspectives of Mobile Learning Platforms: An Empirical Study
}

Muasaad Alrasheedi

Western University

Luiz Fernando Capretz

University of Western Ontario, lcapretz@uwo.ca

Arif Raza

Western University

Follow this and additional works at: https://ir.lib.uwo.ca/electricalpub

Part of the Software Engineering Commons

Citation of this paper:

Alrasheedi M., Capretz L.F. and Raza A. Students' Perspectives of Mobile Learning Platforms: An Empirical Study, International Journal of Technology Enhanced Learning, Volume 7, Issue 4, pp. 378-393, Inderscience, DOI: 10.1504/IJTEL.2015.074193, December 2015. 


\title{
Students' perspectives of mobile learning platforms: an empirical study
}

\section{Muasaad Alrasheedi*, Luiz Fernando Capretz and Arif Raza}

The University of Western Ontario, 1151 Richmond St, London, ON N6A 3K7, Canada

+1 519-661-2111

Email: malrash@uwo.ca

*Corresponding author

\begin{abstract}
Educational institutions are becoming involved in adopting technological innovations like the mobile learning (m-Learning) platform for education. Mobile technologies are the next frontier as infrastructure for m-Learning because they can provide high-quality learning capabilities to satisfy the rising student demand for mobility and flexibility due to the ubiquitous nature of mobile technology (smartphones) and the vast opportunities it offers, there are indications that smartphones could lead the next generation for learning platforms. Researchers have examined the idea from several angles and produced a copious amount of literature devoted to explaining the interrelationships of technology and learning. In this research we aim to offer a view of students' perspectives, giving a systematic examination of m-Learning adoption that can be used as a framework for further research into the success of $\mathrm{m}$-Learning. We found that making learning more interesting, increasing productivity, and providing internet access had the greatest effect on student's perceptions.
\end{abstract}

Keywords: critical success factors; m-learning; mobile learning.

Reference to this paper should be made as follows: Alrasheedi, M., Capretz, L.F., and Raza, A. (2015) 'Students' perspectives of mobile learning platforms: an empirical study', Int. J. Technology Enhanced Learning, Vol. 7, No. 4, pp.378-393.

Biographical notes: Dr. Muasaad Alrasheedi received his $\mathrm{PhD}$ (2015) in Software Engineering Program from Western University, London, Canada. He has a Bachelor of Science degree in Information Technology and Computing from Arab Open University, Saudi Arabia and a Master of Engineering in Technology Innovation Management from Carleton University, Canada. His research interest is in mobile learning and emerging educational technology. $\mathrm{He}$ can be reached at: malrash@uwo.ca.

Dr. Luiz Fernando Capretz is a Professor of Software Engineering and Assistant Dean (IT and e-Learning) at Western University, London, Canada. His research interests include software engineering, technology-enhanced learning, human factors in software engineering and software engineering education. Dr. Capretz has a PhD in computing science from the University of Newcastle upon Tyne. He is a senior member of the IEEE, a distinguished member of the ACM, an MBTI certified practitioner and a Professional Engineer in Ontario (Canada). He can be reached at lcapretz@uwo.ca. 
Dr. Arif Raza received his PhD (2011) in Software Engineering from Western University, Canada. He has authored and co-authored over 20 research articles in peer reviewed journals and conference proceedings. His current research interests include $\mathrm{HCI}$, empirical studies, usability engineering and human factors in SE. He can be reached at araza22@uwo.ca.

\section{Introduction}

Mobile learning (m-Learning) is basically a learning platform in which wireless communication technology and smartphones are used to impart education. This allows students to access their learning materials and information no matter where they are and at any time that is convenient, leveraging the base technology to its fullest. This empowerment of students, giving them the choice of time and location for their learning as well as the pace at which they learn, is changing the way people view education itself (Ally, 2009). Needless to say, this offers exciting possibilities to expand the horisons of education. However, due to the size of the changes involved and their impact, it is often viewed somewhat sceptically by the very people who would benefit most from these changes.

The unique feature of the m-Learning platform that makes it an entirely new educational platform is mobility. The concept of mobility refers to the prospect of having flexibility in terms of time, place, pace, and space that is not achievable when using nonmobile versions of devices (Andrews et al., 2010). In theory, m-Learning offers learners the opportunity to learn at any time and at any place. However, it must be understood that the terms at any time and any place are limited from being universally true due to issues of connectivity as well as safety restrictions (Saccol et al., 2010). It is this combination of mobility and collaborative learning that separates the m-Learning platform from other learning platforms that are available such as technology-focused platforms like e-learning and traditional face-to-face education (Kukulska-Hulme and Taxler, 2007).

The fact that computing power, the internet, and mobile technologies have all increased at the same time has that has led many researchers to equate them when they research the m-Learning platform.

The m-Learning platform has changed the learning paradigm, and it has the potential to alter the way education is imparted. Most of the pilot studies reviewing the adoption and success of m-Learning within universities have tended to focus only on technical capabilities (Kukulska-Hulme, 2005).

The technology behind m-learning depends on the interaction between the machines and the people using them, and thus looking exclusively towards the capabilities of the mobile device and its applications greatly limits the view. The perspective of success factors must also extend to the usage of m-Learning in different contexts (Ally, 2009; Andrews et al., 2010).

This interrelationship has been the subject of a large amount of research and there are different studies published that detail this; however, the majority lacks any kind of systematic analysis despite the quantitative nature of the research. 


\section{Literature review}

This research offers a systematic way of analysing students' perceptions of a successful $\mathrm{m}$-Learning platform that can be emulated in other studies to understand the critical success factors (CSFs) of m-Learning in different contexts. We study and empirically analyse the impact of six CSFs that have had the most effect on the students' perceptions: 1 - the technical competence of students, 2 - the personalisation of the learning program 3 - the ability to make learning interesting, 4-an increase in productivity, 5-the access to the internet, and 6-the accessibility of the platform.

The rapid growth of mobile technology has pushed educational institutions to adopt $\mathrm{m}$-Learning. It has the potential to allow students to closely integrate all of the learning activities in their lives. This study aims to identify factors that affect the perception of students towards the use and adoption of m-Learning. However, the adoption and level of use is determined by several factors (Cochrane, 2013). In this work, we study and empirically analyse the impact of the six key factors that were mentioned above. These factors need to be dealt with to ensure the success of m-Learning.

The first factor, the technical competence of students, refers to the technical knowledge and skills of students; these are key determinants in the success of $\mathrm{m}$-Learning. The ability to use new technology determines a student's acceptance of new technology, such as e-Learning and m-Learning (Park, Nam and Cha, 2012). Lack of skills may hinder an individual's ability to embrace m-Learning. Training in the use of the new system may help an individual to cope and fully use the new platform (Volery and Lord, 2000).

Increased productivity is another critical success factor in m-Learning. The extent to which students believe that they can receive information or digital mobile content through mobile devices with serviceable and appropriable quality determines the quality of their m-Learning, which in turn determines their level of productivity (Woodill, 2012). A higher quality of mobile content could completely determine the student's interest in adopting $\mathrm{m}$-Learning for their learning experience. The higher quality of content and the ability to customise the system are of great importance in the student level of satisfaction with the mobile technology; this in turn leads to utilisation of m-Learning and an increase in student productivity levels. In other words, the quality of the content in m-Learning increases the productivity of the students and enhances their level of success in the job market (Abachi and Muhammad, 2014).

Personalisation is a third factor determining the success of m-Learning; it refers to a student's self-perception and self-management in being capable of succeeding in learning tasks. The individualisation of mobile learning to suit the individual needs of the student also determines the efficiency of learning. In this case, it refers to student perception and management of using m-Learning in the learning process. The use of m-Learning successfully enhances the teaching and learning process when students are fully ready and feel personally valued (Liaw, Hatala and Huang, 2010). Personalisation also refers to the practice of dynamically customising your site to suit your purposes and intent. The practice of personalisation differs from one student to the other with regards to $\mathrm{m}$-Learning, personalisation will be of help to the m-Learning students since they will be in a position to design and fashion their learning materials in a way they can best comprehend these concepts. This has the general effect of enhancing the understanding of the concepts for the m-Learning students (Cheung, 2014). 
It is generally accepted that there are two adaptive approaches to personalisation (Kinshuk, Graf and Yang, 2009), the first is that the learning service itself can adapt to individual learner characteristics. This includes their requirements, learning styles, profiles, performance, and status. The second approach is that the learning service adapts to the context surrounding the learners. Of the two, the first is easier to understand and a way to best illustrate this concept would be for learners who have shown better performance from a visual learning style to receive the service using multimedia materials. The second approach relies on the context-awareness of the learning service, which is a slightly more difficult concept to grasp. An illustration of this approach in action would be for someone to be learning in a library supplied with learning material in a book form, which best suits the context of the learner (Kinshuk, Graf and Yang, 2009).

There are currently many learning technologies available that use different mobile platforms, including mobile phones or PDA devices. The idea behind these platforms is to support an anytime-anywhere learning experience and, indeed, in pilot studies the level of engagement and interest within the students is comparable to the response to computer labs (Nedungadi and Raman, 2012). Additionally, m-Learning delivers a level of personal interaction that cannot be matched by other learning methodology and can be utilised to provide excellent feedback on the progress of the learner (Sampson and Zervas, 2013).

A fourth critical factor in the success of m-Learning is making learning interesting and enjoyable. Every student expects that the use of new technology will enhance their performance by making learning interesting. The m-Learning system, therefore, needs to demonstrate the usefulness of context awareness support, providing appropriate information to support a student's study experience. In addition, the use of m-Learning as an interactive tool in education could increase the communication between students and lecturers (Mazzarol, 1998). This relationship makes the m-Learning experience a participative venture where every individual need is met and valued. This makes learning interesting since there is no fear, no criticism, and no rejection. The students learn from each other, which increases the intrinsic and extrinsic motivation towards learning (Monchai, 2014).

The fifth factor is internet access. The extent to which students are able to easily access the network to gain information through mobile devices is a CSF in m-Learning (Shunye, 2014). This concept is built upon the concepts of mobility, convenience, and the anywhere-anytime paradigm upon which m-Learning is based. Internet access has a great influence on the students who use m-Learning because it helps to fully mediate the intentions to use m-Learning (Gupta and Manjrekar, 2012).

The sixth, and final, factor is platform accessibility. Here the platform means the various systems, such as the iOS system, Android, Blackberry, and Windows (Pocatilu, 2013). This also includes diverse hardware manufacturers for platforms such as HTC, Google, Samsung, and Apple (Sarrab, Elgamel and Aldabbas, 2012). This factor contributes positively to the use of m-Learning among students, as they are able to access the learning materials anywhere and in different designs as long as they have the appropriate handheld computing device.

\section{Research model and hypotheses}

In this section we present a research model for analysing the relationship between key CSFs and students' perspectives towards m-Learning, as shown in Figure 1. The model 
derives its theoretical foundations by combining the previous work by (Alrasheedi and Capretz, 2013; Alrasheedi, Capretz and Raza, 2015). The model uses six CSFs: 1 - the technical competence of students, 2 - the personalisation of m-Learning, 3-the ability to make learning interesting, 4-an increase in productivity, 5-the access to the Internet, and 6-the accessibility of the platform. The dependent variable of this study is $\mathrm{m}$-Learning adoption according to students' perceptions. The six independent variables are referred to as CSFs hereafter. Overall, the objective of this study is to investigate the answer to the following question:

"To what extent do the critical success factors have an impact on m-Learning adoption based on the perception of university students?"

Figure 1 Research model-CSFs affecting the success of m-learning adoption according to students' perceptions

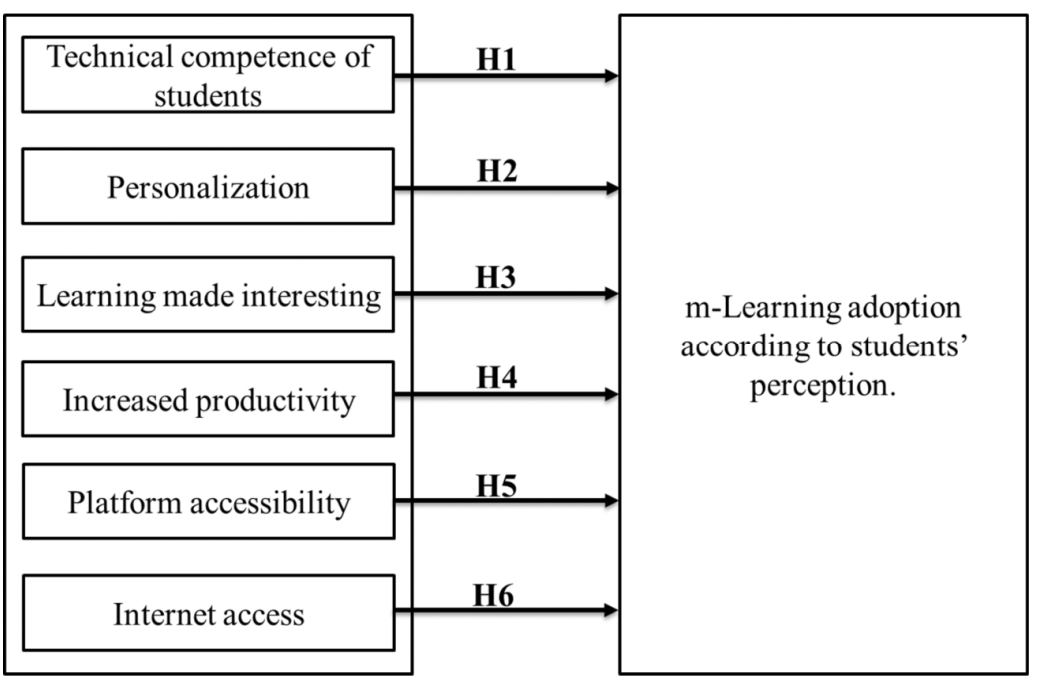

In this context we have six hypotheses to be tested:

Hypothesis 1. The technical competence of students positively affects the m-Learning adoption according to students' perceptions.

Hypothesis 2. The extent of personalisation positively affects m-Learning adoption according to students' perceptions.

Hypothesis 3. The possibility of interesting ways of learning the course matter is positively related to the m-Learning adoption according to students' perceptions.

Hypothesis 4. Increased productivity plays a positive role towards m-Learning adoption.

Hypothesis 5. Improved internet access has a positive impact on m-Learning adoption by students.

Hypothesis 6. Improved platform accessibility is positively related to m-Learning adoption according to the students' perceptions. 
Undoubtedly, students are the target user group around which the entire platform has been built and, hence, their attitudes are extremely important. Our previous research found six factors that affect the overall attitude towards the m-Learning platform (Alrasheedi and Capretz, 2015). To determine user satisfaction levels, we have conducted a detailed survey targeting students who are using the m-Learning platform. The multiple linear regression equation of the model is as follows:

m-Learning adoption as per students' perceptions $=c_{0}+c_{1} f_{1}+c_{2} f_{2}+c_{3} f_{3}+c_{4} f_{4}+$ $\mathrm{c}_{5} \mathrm{f}_{5}+\mathrm{c}_{6} \mathrm{f}_{6}$.

In the equation $\mathrm{c}_{0}, \mathrm{c}_{1}, \mathrm{c}_{2}, \mathrm{c}_{3}, \mathrm{c}_{4}, \mathrm{c}_{5}$ and $\mathrm{c}_{6}$ are coefficients and $\mathrm{f}_{1}, \mathrm{f}_{2}, \mathrm{f}_{3}, \mathrm{f}_{4}, \mathrm{f}_{5}$ and $\mathrm{f}_{6}$ are the six independent variables. To empirically investigate the research question, the six hypotheses are presented with a belief that they all positively affect m-Learning adoption according to students' perceptions.

\section{Research methodology}

As students form the largest user group, the present study focuses on gathering their opinions in a systematic manner; and our methodology is presented in Figure 2. First, we systematically identified the factors contributing directly or indirectly to m-Learning adoption from the students' perspective. In order to do an empirical investigation of the key factors from the students' perspective, a research model was developed based on the key factors shown in Figure 1. After this, a questionnaire was prepared and we conducted a survey to assess each key factor. Finally, we performed a statistical analysis of data on students' perspectives. The analysis was performed using quantitative tools, specifically Minitab v.17.

Figure 2 Steps representing the research methodology

Systematic literature review to come up with the factors that contribute directly or indirectly from student perspectives

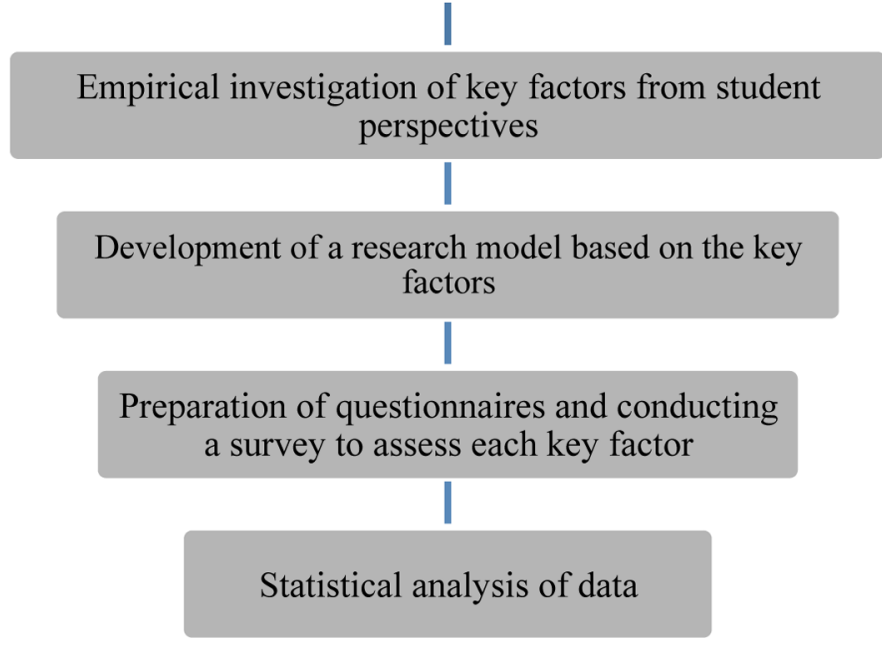




\section{Data collection and the measuring instrument}

To collect the data, we used an online survey tool (So Go Survey) and the questionnaire was sent to various undergraduate students of different faculties in five universities in Saudi Arabia. We assured the students that the survey was confidential: their identity would not be disclosed and their primary responses would only be used for this study. We received a total of 202 completed questionnaires.

The measuring instruments presented in Appendix I were used to study the perceived level of student satisfaction as well as the extent to which these CSFs were important for the students in adopting m-Learning. The questionnaire required participants to indicate the extent of their agreement or disagreement with statements using a five-point Likert scale. For all of the items associated with each variable, the scale was $(1=$ Strongly Disagree, 2 = Disagree, $3=$ Neither Agree or Disagree, $4=$ Agree, $5=$ Strongly Agree).

Our questionnaire had three parts:

1. The first part was used to determine the general profile of the respondents and consisted of questions regarding their gender, age group, and educational status.

2. The second part was used to determine the extent to which students have access to mobile devices and the internet, and their experience in using these devices.

3. The third part was used to determine the different factors that affected user perception of the m-Learning platform as below: Question 1 (Technical competence of students), Question 2 (Personalisation), Question 3 (Learning made interesting), 4-7 (increased productivity), Questions 8-11 (Platform accessibility), Questions 12-14 (internet access), and Questions 15-17 (Cumulative overall perception of $\mathrm{m}$-Learning adoption, in this case from students' the perspectives).

\section{Data analysis method}

We started our data analysis by making a descriptive analysis of the demographic distribution of the population. Then, in order to analyse the research model and test the hypotheses, the data analysis procedure involved three steps. First, a parametric correlation was found between the dependent and independent variables to see if any of the variables, i.e., hypotheses, could be rejected. The second step was conducted making a non-parametric correlation using the same set of data in order to reduce the threat to an external validity (Raza, Capretz and Ahmed, 2012). Finally, the third step involved testing the hypotheses by using the partial least square (PLS) technique.

\section{Demographic distribution of the population}

This section provides a description of the demographic distribution of the survey population. The total population of the research consisted of 202 undergraduate students studying in different departments in five universities in Saudi Arabia.

The gender distribution of the population consisted of 123 male students and 78 female students. Only one person did not answer the question of respondent distribution illustrated in Figure 3. The age distribution of the population is as follows. A majority of 
the population was younger than 25 years, 132 persons and No respondents were older than 55 years and four persons chose not to answer this question. Forty-seven of the respondents were aged 26-35 years, and 19 of the respondents were aged 36-55 years. The research population consisted of 146 full-time students and 55 part-time students. One person did not answer this question. As shown in Figure 4125 students were studying computer science and IT; 38 students were in other engineering branches; 7 were social sciences students; 4 were health sciences students, and 2 were agriculture students. 15 were studying other courses. The research also investigated the mobile usage demographics of the research population. All 202 students owned mobile phones and smartphones.

Figure 3 Respondents' gender distribution (see online version for colours)

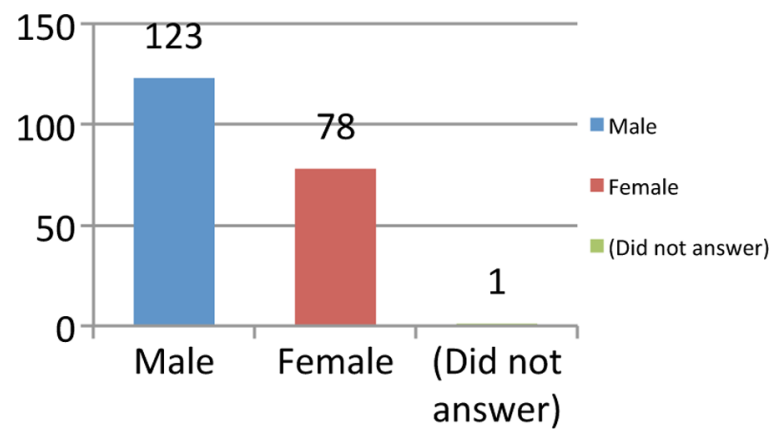

Figure 4 Respondents' faculty distribution (see online version for colours)

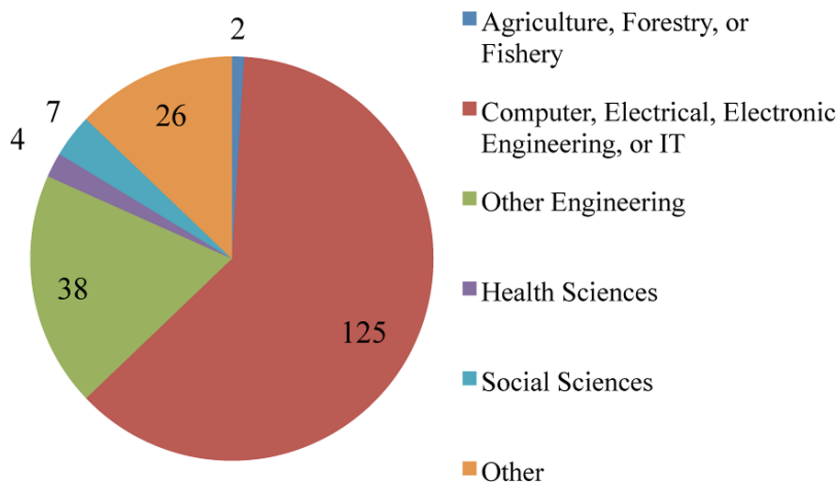

\section{Reliability and validity analysis of the measuring instrument}

Among the responses of the questionnaire regarding perception of various aspects of the m-Learning platforms, three are straightforward and involve single-item measurement scales. However, the remaining three factors are measured using multi-item rating scalesstudent productivity, platform accessibility, and internet access. The dependent variable also involves the use of a multi-item rating scale. In these particular cases, it is important 
to assess the reliability of the measurement scales. Reliability analysis indicate the reproducibility of a measurement. We have done an internal consistency analysis to calculate the Cronbach's alpha. Various researchers have cited different satisfactory levels for the reliability coefficient. As an example, van de Ven and Ferry believe that a coefficient of 0.55 and higher is satisfactory (van de Ven and Ferry, 1980). However, recent researchers such as Osterhof, believe that the coefficient must be at least 0.6 (Osterhof, 2001). In our case, the reliability coefficient is $>0.63$ in all the cases, which means that the measuring instruments used are reliable. Table 1 below shows the values of Cronbach's alpha for the factors discussed.

Table 1 Cronbach's alpha for multi-measuring rating scales

\begin{tabular}{lccc}
\hline Success factors & Item numbers & Cronbach's alpha & PCA Eigen values \\
\hline $\begin{array}{l}\text { Technical } \\
\text { competence of } \\
\text { student }\end{array}$ & 1 & 0.7621 & 1.6258 \\
$\begin{array}{l}\text { Personalisation } \\
\text { Learning made }\end{array}$ & 2 & & \\
$\begin{array}{l}\text { interesting } \\
\begin{array}{l}\text { Increased } \\
\text { productivity }\end{array}\end{array}$ & 3 & 0.6305 & 1.4632 \\
$\begin{array}{l}\text { Platform } \\
\text { accessibility }\end{array}$ & $8-7$ & 0.7553 & 1.6134 \\
Internet access & $12-14$ & 0.8922 & 1.7502 \\
\hline
\end{tabular}

Validity is the strength of the inference of the true value starting from the value of a measurement. Comrey and Lee's (1992) Principal Component Analysis (PCA) was performed for all six CSFs, and reported in Table 1. We used an Eigen value (Kaiser, 1970) as a reference point to observe the construct validity, using PCA. We used the Eigen Value one criterion, which is known as the Kaiser Criterion (Kaiser, 1960; Stevens, 1986) that indicated any component having an Eigen value more than one would be retained. In our study, the Eigen-value analysis discovered that all six variables come from a single factor, as presented in Table 1 . Therefore, according to our statistical analysis, the convergent validity of our instrument for m-Learning adoption according to students' perspectives can be considered as sufficient.

\section{Hypothesis tests and results}

We analysed the research model and the significance of hypotheses H1-H6, using different statistical techniques in three phases. In phase I we used normal distribution tests and parametric statistics, whereas in phase II we used non-parametric statistics. Both parametric as well as non-parametric statistical approaches were used to reduce the threats to external validity. As our measuring instrument had multiple items for all six independent variables as well as the dependent variable (as shown in Appendix I), the ratings by the respondents were added up to get a composite value for each rating. Tests were conducted for hypotheses H1-H6 using parametric statistics by determining the Pearson correlation coefficient. For non-parametric statistics, tests were conducted for 
hypotheses H1-H6 by determining the Spearman correlation coefficient. To increase the reliability of the results, hypotheses $\mathrm{H} 1-\mathrm{H} 6$ of the research model were tested using the PLS technique in Phase III. The results of the statistical calculation for the Pearson correlation coefficient are shown in Table 2. It is well known that the lower the p-value the better the chance of rejecting the null hypothesis and, hence, the more significant the result in terms of its statistical significance (Stigler, 2008). The significance of each coefficient was indicated in terms of $p$-values; in the present case all $p$-values are $<0.05$. This indicates that the results are significant.

Table 2 Hypothesis testing using a parametric test

\begin{tabular}{llcc}
\hline Hypothesis & \multicolumn{1}{c}{ Critical success factor } & $\begin{array}{c}\text { Pearson correlation } \\
\text { coefficient }\end{array}$ & $\begin{array}{c}\text { Spearman correlation } \\
\text { coefficient }\end{array}$ \\
\hline H1 & Technical competence of students & $0.626^{*}$ & $0.613^{*}$ \\
H2 & Personalisation & $0.463^{*}$ & $0.442^{*}$ \\
H3 & Learning made interesting & $0.613^{*}$ & $0.606^{*}$ \\
H4 & Student productivity & $0.750^{*}$ & $0.727^{*}$ \\
H5 & Platform accessibility & $0.630^{*}$ & $0.616^{*}$ \\
H6 & Internet access & $0.610^{*}$ & $0.574^{*}$ \\
\hline
\end{tabular}

*Significant at $P<0.05$

The Pearson correlation coefficient between the technical competence of students towards m-Learning and m-Learning adoption was positive: 0.626 at $P<0.05$, and, hence, hypothesis $\mathrm{H} 1$ is justified. For $\mathrm{H} 2$, the relationship between personalisation and m-Learning adoption, the Pearson correlation coefficient, was 0.463 at $P<0.05$, and, hence, it was found to be significant as well. Furthermore, hypothesis H3 was accepted based on the Pearson correlation coefficient of 0.613 at $P<0.05$, which represents the relationship between learning made interesting and m-Learning adoption. Similarly, hypothesis H4, which denotes the relationship between student productivity and m-Learning adoption, yields a Pearson correlation coefficient of 0.750 at $P<0.05$. This hypothesis is statistically significant, and, consequently, it was accepted. For H5, the relationship between platform accessibility and m-Learning adoption, the Pearson correlation coefficient was 0.630 at $P<0.05$; hence, it was found to be significant and was accepted as well. Likewise, hypothesis H6 was accepted based on the Pearson correlation coefficient of 0.610 at $P<0.05$, which represents the relationship between internet access and students' perceptions towards m-Learning. Hence, as observed and reported, all hypotheses- $\mathrm{H} 1, \mathrm{H} 2, \mathrm{H} 3, \mathrm{H} 4, \mathrm{H} 5$, and $\mathrm{H} 6$ - were found to be statistically significant and were accepted.

In the second step, non-parametric statistical testing was performed by examining the Spearman correlation coefficient including the individual independent variables, all CSFs, and the dependent variable, m-Learning adoption according to students' perceptions, as shown in Table 2.

\subsection{PHASE-II}

Non-parametric statistical testing was conducted in this phase by examining Spearman correlation coefficients between individual independent variables (CSFs) and the 
dependent variable (m-Learning adoption). The results of the statistical calculations for the Spearman correlation coefficients are also displayed in Table 2. The Spearman correlation coefficient between the technical competence of students and m-Learning adoption according to students' perceptions was positive, i.e., 0.613 at $P<0.05$, and, hence, hypothesis $\mathrm{H} 1$ was justified. For hypothesis $\mathrm{H} 2$, which examined the relationship between personalisation and m-Learning adoption, the Spearman correlation coefficient of 0.442 was observed at $P<0.05$, which indicates that this hypothesis was significant. Moreover, hypothesis $\mathrm{H} 3$ was accepted based on the Spearman correlation coefficient of 0.606 at $P<0.05$, representative of a statistically significant relationship between learning made interesting and m-Learning adoption. For hypothesis H4, which involves student productivity and $\mathrm{m}$-Learning adoption, the Spearman correlation coefficient of 0.727 was observed at $P<0.05$. Since a significant relationship was found between productivity and m-Learning, $\mathrm{H} 4$ was accepted. For H5, the relationship between platform accessibility and $\mathrm{m}$-Learning adoption, the Spearman correlation coefficient was 0.616 at $P<0.05$, which means it was found to be significant; consequently, it, too, was accepted. Similarly, hypothesis H6 was accepted based on the Spearman correlation coefficient of 0.574 at $P<0.05$, which represents the relationship between internet access and m-Learning adoption according to the students' perceptions. Therefore, as observed and reported, all hypotheses- $\mathrm{H} 1, \mathrm{H} 2, \mathrm{H} 3, \mathrm{H} 4, \mathrm{H} 5$, and $\mathrm{H} 6$ - were found to be statistically significant and were accepted.

\subsection{PHASE-III}

In order to do the cross-validation of the results obtained in Phase I and Phase II, the PLS technique was used in this phase of hypothesis testing. Fornell and Bookstein (1982) reported that the PLS technique is particularly valuable in different circumstances, including complexity, non-normal distribution, low theoretical information, and small sample size. Accordingly, the PLS technique was used to increase the reliability of the results.

In the PLS approach, the dependent variable of our research model (m-Learning adoption according to students' perceptions) is considered as the response variable, and the independent variables (CSFs) are considered as predicators. The test outcomes, which contain the observed values of the path coefficient $R^{2}$ and the $F$-ratio, are illustrated in Table 3. The technical competence of students is observed to be significant at $P<0.05$ with a path coefficient of 0.52 , an $R^{2}$ value of 0.39 , and an $F$-ratio of 128.7 . Personalisation has a path coefficient of 0.41 , an $R^{2}$ value of 0.21 , and an $F$-ratio of 54.6. Learning made interesting has the same direction as proposed in hypothesis $\mathrm{H} 3$, with a path coefficient of 0.52 , an $R^{2}$ value of 0.37 , and an $F$-ratio of 120.6. The variable of student productivity had a path coefficient of 0.80 , an $R^{2}$ value of 0.56 , and an $F$-ratio of 257.4. The variable of platform accessibility had a path coefficient of 0.63 , an $R^{2}$ value of 0.39 , and an $F$-ratio of 131.8 . Finally, the variable of internet access had a path coefficient of 0.65 , an $R^{2}$ value of 0.37 , and an $F$-ratio of 118.3 . 
Table 3 Hypotheses testing using partial least square regression

\begin{tabular}{llccc}
\hline Hypothesis & \multicolumn{1}{c}{ Factor } & Path coefficient & $R^{2}$ & F-Ratio \\
\hline H1 & Technical competence of students & 0.52 & 0.39 & $128.7^{*}$ \\
H2 & Personalisation & 0.41 & 0.21 & $54.6^{*}$ \\
H3 & Learning made interesting & 0.52 & 0.37 & $120.6^{*}$ \\
H4 & Increased productivity & 0.80 & 0.56 & $257.4^{*}$ \\
H5 & Platform accessibility & 0.63 & 0.39 & $131.8^{*}$ \\
H6 & Internet access & 0.65 & 0.37 & $118.3^{*}$ \\
\hline
\end{tabular}

*Significant at $P<0.05$

\section{Testing the research model}

The multiple linear regression equation of our research model is depicted by Equation-1. The purpose of research model testing was to provide empirical evidence that our CSFs play a significant role towards m-Learning adoption. The testing process consisted of conducting regression analysis, and reporting the values of the model coefficients and their direction of association. We placed m-Learning adoption as a response variable and CSFs as predicators. Table 4 shows the regression analysis results of the research model.

Table 4 Multiple regression analysis of the research model

\begin{tabular}{lccc}
\hline Critical success factor & Coefficient term & Coefficient value & t-Value \\
\hline Technical competence of student & f1 & 0.0812 & $1.57^{* *}$ \\
Personalisation & f2 & -0.0919 & $-1.81^{* *}$ \\
Learning made interesting & $\mathrm{f} 3$ & 0.2105 & $4.10^{*}$ \\
Increased productivity & $\mathrm{f} 4$ & 0.4079 & $5.09^{*}$ \\
Platform accessibility & $\mathrm{f} 5$ & 0.1116 & $1.72^{* *}$ \\
Internet access & $\mathrm{f6}$ & 0.2526 & $3.93^{*}$ \\
\hline
\end{tabular}

* Significant at $P<0.05, * *$ Insignificant $>=0.05$

The results of the statistical calculations for the multiple regressions are displayed in Table 4. The $t$-value for the technical competence of students and $\mathrm{m}$-Learning adoption according to students' perceptions was 1.57 at $P>0.05$, and, hence, it is insignificant. The t-value between Personalisation and m-Learning adoption according to students' perceptions was observed negative at $(-1.81)$ and the $P>0.05$, which indicates that it, too, was insignificant. However, the $t$-value was 4.10 and the $P<0.05$, illustrative of a statistically significant relationship between Learning made interesting and $\mathrm{m}$-Learning adoption according to the students' perceptions. Then, the $t$-value for increased productivity and m-Learning adoption according to the students' perceptions, was observed equal to 5.09 at $P<0.05$. Since a significant relationship was found between increased productivity and students' perceptions towards m-Learning, H4 was accepted. For H5, the relationship between platform accessibility and m-Learning adoption according to the students' perceptions, the t-value was observed to be 1.72 at $P>0.05$, which means it was found to be insignificant; consequently, it was rejected. The last 
hypothesis, H6, was accepted, based on the $t$-value of 3.93 at $P<0.05$, which represents the relationship between internet access and m-Learning adoption according to students' perceptions. Therefore, the first interesting part of the analysis is that not all the coefficients are positive. Personalisation has a negative coefficient. Similarly, the factors like, the technical competence of students and platform accessibility were found to be insignificant since their corresponding $p$-values were $>0.05$. Hence, the corresponding hypotheses $\mathrm{H} 1, \mathrm{H} 2$, and $\mathrm{H} 5$ were rejected.

The final regression equation is as follows:

Students' perceptions $=0.239+0.0812$ (Technical competence students) -0.0919 (Personalisation) +0.2105 (Learning made interesting) +0.4079 (Increased productivity) +0.1116 (Platform accessibility) +0.2529 (Internet access)

As can be seen, personalisation is negative in this case. The model accounts for $66.05 \%$ variability in the dependent variable, i.e., m-Learning adoption from students' perceptions.

\section{Discussion}

The data analysis of the survey covers only a limited section of the results. The gender distribution was skewed towards male students, but female students were a significant part of the population. A majority of the students were under the age of 25 and in fulltime undergraduate study. Finally, the student population consisted mainly of computer and other engineering students. Some of the questionnaire consisted of multiple-response rating scales, and so the first step constituted determining whether the overall responses were valid. The values of Cronbach's alpha in the relevant parameters (student productivity, platform accessibility, internet access, and the dependent variable, $\mathrm{m}$-Learning adoption, were all found to be higher than 0.63 , which was above the most recently decided threshold of 0.6 . Hence, the averages of the response could be used for determining the individual variable coefficients in the research mode.

In order to remove the threats to external validity, both parametric and nonparametric studies were carried out. The coefficients were similar in both tests, though the Spearman's Rho tended to be somewhat lower than Pearson's coefficient. More importantly, none of the hypotheses could be rejected at this stage because, statistically speaking, all were found to be significant with a $P$-value of $<0.05$. The next crucial result was that none of the correlation coefficients were lower than 0.4 , suggesting that the data was at least fairly correlated and none of the hypotheses could be rejected based on the issue of poor correlation.

Armed with this information, the next step constituted determining the regression equation for the research model. The regression analysis showed that three out of six variables were statistically significant and, hence, H3, H4 and H6 were accepted. All of the variables except personalisation had the expected direction based on the original hypotheses.

\section{Limitation of the study}

The present research was detailed in terms of the analysis of student responses. However, there are certain limitations and they are mostly related to the analysis of data. 
As in the case of any empirical investigation, this study has certain limitations. Easterbrooks et al. (2007) refer to construct validity, internal validity, external validity, and reliability as four criteria of validity in an empirical study. In most cases, the researcher's ability to generalise the experimental outcome to industrial practice is generally limited by threats to external validity (Wohlin et al., 2000), which is the case with this study. We took specific measures to support external validity, including our use of a random sampling technique that selects respondents from all departments to at least represent the general population of students within the university.

Furthermore, another aspect of validity concerns whether or not the study results correspond to previous findings. Our work involved the selection of five independent variables that related to the dependent variable of student's perspectives. While there are other key factors that influence m-Learning adoption, the scope of this study was restricted to the area of $\mathrm{m}$-Learning adoption from the perspective of students.

Another limitation of this study involves its relatively small sample size. Although, we sent our survey to a large number of students who were enrolled in five universities, we only received 202 responses. Consequently, the relatively small number of responses was a potential threat to the external validity. However, we followed the appropriate research procedures by conducting and reporting tests in order to improve the reliability and validity of the study, and certain measures were also taken to increase the external validity.

\section{Conclusion}

The present study conducted a systematic and detailed investigation into the factors affecting students' perceptions that is based on a survey taken from students of five universities in Saudi Arabia. The purpose was to understand the specific factors that affected students' perceptions at the higher education levels. Additionally, determining the extent of the effect of individual factors was a related objective. The results of the analysis showed that the following parameters were found to be significant to m-Learning adoption according to students' perceptions: Learning made interesting, increased productivity, and internet access. The study conducted and reported here will enable $\mathrm{m}$-Learning software designers and developers to better understand the effectiveness of the relationships of the stated key factors and m-Learning adoption of their projects. Currently we are working on developing a maturity model to assess the m-Learning adoption among different communities of end users. This empirical investigation provides us some justification to consider these key factors as measuring instruments.

\section{References}

Abachi, H.R. and Muhammad, G. (2014) 'The impact of m-learning technology on students and educators', Computers in Human Behavior, Vol. 30, pp.491-496.

Ally, M. (2009) Mobile Learning: Transforming the Delivery of Education and Training, Athabasca University Press, Edmonton, Alberta, Canada.

Alrasheedi, M. and Capretz, L.F. (2013) 'A meta-analysis of critical success factors affecting mobile learning', IEEE International Conference on Teaching, Assessment and Learning for Engineering, IEEE, Bali, Indonesia, August 26-29, 2013, pp.262-267. 
Alrasheedi, M. and Capretz, L.F. (2015) 'Determination of critical factors affecting mobile learning: a meta-analysis approach', Turkish online journal of educational technology, Vol. 14, No. 2, pp.41-51.

Alrasheedi, M., Capretz, L.F., \& Raza, A. (2015). A systematic review of the critical factors for success of mobile learning in higher education (University Students' Perspective). Journal of Educational Computing Research, Vol. 52, No. 2, pp.257-276.

Andrews, T. Smyth, R. Tynan, B. Berriman, A. Vale, D. and Cladine, R. (2010) 'Mobile technologies and rich media: expanding tertiary education opportunities in developing countries', In Abdel-Wahab, A.G. and El-Masry, A.A.A. (Eds.): Mobile Information Communication Technologies Adoption in Developing Countries: Effects and Implications, Idea Group Inc., New York, pp.103-116.

Cheung, R. (2014) 'Predicting user intentions for mobile learning in a project-based environment', International Journal of Electronic Commerce Studies, Vol. 4, No. 2, pp.263-280.

Cochrane, T. (2010b) 'Exploring mobile learning success factors', Research in Learning Technology, Vol. 18, No. 2, pp.133-148.

Comrey, A.L. and Lee, H.B. (1992) 'A First Course on Factor Analysis', 2nd ed., Hillsdale.

Easterbrooks, S., Singer, J., Storey, M.A. and Damian, D. (2007) 'Selecting empirical methods for software engineering research', International Conference on Automated Software Engineering, Atlanta, Georgia, USA.

Fornell, C. and Bookstein, F.L. (1982) 'Two structural equation models: LISREL and PLS applied to consumer exit voice theory', Journal of Marketing Research, Vol. 19, pp.440-452.

Gupta, M. and Manjrekar, P. (2012) 'Using mobile learning to enhance quality in higher education', SIES Journal of Management, Vol. 8, No. 1, pp.23-30.

Kaiser, H.F. (1960) 'The application of electronic computers to factor analysis', Educational and Psychological Measurement, Vol. 20, pp.141-151.

Kaiser, H.F. (1970) ‘A second generation little jiffy', Psychometrika, Vol. 35, pp.401-417.

Kinshuk, C.M., Graf, S. and Yang, G. (2009) 'Adaptivity and personalization in mobile learning', In 2009 AERA Annual Meeting, April 13-17, 2009, San Diego, CA, USA, pp.164-174.

Kukulska-Hulme, A. (2005) 'Introduction', In Kukulska-Hulme, A. and Traxler, J. (Eds.): Mobile Learning: A Handbook for Educators and trainers, Roultedge, New York, pp.1-6.

Kukulska-Hulme, A. and Taxler, J. (2007) 'Designing for mobile and wireless learning', In Beetham, H. and Sharpe, R. (Eds.): Rethinking Pedagogy for a Digital Age: Designing and Delivering e-Learning, Routledge, London, pp.180-192.

Liaw, S.S., Hatala, M. and Huang, H.M. (2010) 'Investigating acceptance toward mobile learning to assist individual knowledge management: based on activity theory approach', Computers \& Education, Vol. 54, No. 2, pp.446-454.

Mazzarol, T. (1998) 'Critical success factors for international education marketing', International Journal of Educational Management, Vol. 12, No. 4, pp.163-175.

Nedungadi, P. and Raman, R. (2012) 'A new approach to personalization: integrating e-learning and m-learning', Educational Technology Research and Development, Vol. 60, No. 4, pp.659678.

Osterhof, A. (2001) Classroom Applications of Educational Measurement, Prentice Hall, New Jersey.

Park, S.Y., Nam, M.W. and Cha, S.B. (2012) 'University students' behavioral intention to use mobile learning: evaluating the technology acceptance model', British Journal of Educational Technology, Vol. 43, No. 4, pp.592-605.

Pocatilu, P. (2013) 'Developing an m-learning application for iOS', Informatica Economica, Vol. 17, No. 4, pp.77-86.

Raza, A., Capretz, L.F. and Ahmed, F. (2012) Users' perception of open source usability: an empirical study', Engineering with Computers, Vol. 28, No. 109, pp.109-121. 
Saccol, A., Barbosa, J.L., Schlemmer, E. and Rienhard, N. (2010) 'Corporate m-learning: applications and challenges', In Guy, R. (Ed.): Mobile Learning: Pilot Projects and Initiatives, Information Science Press, California, pp.215-242.

Sampson, D.G. and Zervas, P. (2013) 'Context-aware adaptive and personalized learning systems', In Sampson, D.G., Isaias, P., Ifenthaler, D. and Spector, J.M. (Eds.): Ubiquitous and Mobile Learning in the Digital Age, Springer, New York, pp.3-18.

Sarrab, M., Elgamel, L. and Aldabbas, H. (2012) 'Mobile learning (m-learning) and educational environments', International Journal of Distributed and Parallel Systems, Vol. 3, No. 4, pp.31-38.

Shunye, W. (2014) 'A new m-learning system for higher education', Journal of Chemical and Pharmaceutical Research, Vol. 6, No. 7, pp.1301-1307.

Stevens, J. (1986) Applied Multivariate Statistics for the Social Sciences, Hillsdale, NJ.

Stigler, S. (2008) 'Fisher and the 5\% level', Chance, Vol. 21, No. 4, p.12.

Van de Ven, A.H. and Ferry, D.L. (1980) 'Measuring and Assessing Organizations, John Wiley and Sons, New York.

Volery, T. and Lord, D. (2000) 'Critical success factors in online education', International Journal of Educational Management, Vol. 14, No. 5, pp.216-223.

Wohlin, C., Runeson, P., Host, M., Ohlsson, M.C., Regnell, B. and Wesslen, A. (2000) 'Experimentation in Software Engineering', Kluwer Academic Publishers, Norwell, MA.

Woodill, G. (2012) 'Moving from e-learning to m-learning', Canadian Learning Journal, Vol. 16, No. 2, pp.34-35. 